\title{
Compound simulated annealing optimization algorithm for real time electricity pricing
}

\author{
Ming-Yuan Cho*, Jyh-Ming Chang \\ Electrical Department, National Kaohsiung University of Science and Technology, Kaohsiung ,Taiwan
}

\begin{abstract}
This approach aims to develop an algorithm for dealing with real time electricity price. The impact factor and different portfolio of cost function including fuel cost, load valve effects, carbon dioxide emissions and capacitor displacement are contained in the calculation. The derived theory is an initiative of green energy pricing mechanism in a power system. The Standard IEEE 30-bus test system and its network branch data are put into practice to verify the model concepts. Compound Simulated Annealing and MATPOWER algorithm (CSAM) is capable of solving AC and DC types of optimal power flow problems with multiple discrete and continuous variables. Marginal cost pricing and cost of marginal carbon emissions comprise the basic elements of electricity price. The uniform and locational electricity price is calculated in the test systems separately. The results show this model is a fast speed and accurate solution solvers of electricity price. Moreover, real time energy price with cost of carbon emissions makes users pay a little bit more for their electricity consumption. It is not only to have an attitude of seeking energy-saving, but even to achieve a basis structure of green energy pricing movement.
\end{abstract}

Keywords: Impact factor, marginal carbon emissions cost, compound simulated annealing optimization

\section{Introduction}

Recently, an increased concern upon environmental protection has become a main trend. Restrictions of carbon emissions of conventional power generation plant play an important role in this matter. This article is intended as building an algorithm for dealing with real time electricity price. The impact factor and carbon dioxide emissions are comprehended in the process of electricity price calculation. A green energy pricing mechanism is initiated from the model derived in this work. Fairer and more equal energy price is possible to impel the environment to become sustainable.

Much literature has been carried on relevant studies. Evolutional programming algorithms have been applied to cope with dispatching electric power regarding economic and environmental courses [1]-[3]. Great deals of earlier work [4]-[17] have focused on LMP-related (locational marginal pricing) research results. About modeling of LMPs and its decomposed components has been performed in [4]-[12]. Sensitivity of LMP is discussed in [12]-[13]. Li [14] proposed a modification of LMP methodology. Forecasting of LMP considering load variation and uncertainty was presented in [15]-[16]. Chen [17] argued a methodology to directly link each concerned factors to the nodal prices.

The model concept which details a mathematical formula in the pricing computations is the beginning. Problem formulation will follow to illustrate how to really implement the procedure and achieve the goals. Furthermore, some numerical results in case studies will be presented afterwards to prove the accuracy of the proposed model. The standard IEEE-30 bus test system and branch data are applied as electric system networks. Finally, the conclusion contains a brief conclusion and further investigations in the future.

\footnotetext{
* Manuscript received June 10, 2018; revised April 29, 2019.

Corresponding author. Tel.: +886-931820911; E-mail address: 1103404104@gm.kuas.edu.tw.. 


\section{Model Concept}

Concept of impact factors originates from some generators which have more influential effects in consequence of their cost function or specific location in the physic power network. The impact factors are designed for compensating generators or plants. The more critical role it may play, the more weighting it can get. With a view to finding the impact of one generator, the first equation refers to (1).

$$
\left|P_{G i j}-P_{G i, O P F}\right|=\Delta P_{G i j}
$$

where,

$\mathrm{P}_{\mathrm{Gij}}$ : MW generated by generator i due to a demand change in bus $\mathrm{j}$

$\mathrm{P}_{\mathrm{Gi}, \mathrm{OPF}}$ : $\mathrm{MW}$ generated by generator $\mathrm{i}$ in an optimal power flow solution

$\Delta \mathrm{P}_{\mathrm{Gij}}$ : difference of MW generated by generator $\mathrm{i}$ due to a demand change in bus $\mathrm{j}$ and an optimal power flow solution

An index $\mathrm{P}_{\mathrm{Gi}}$,ind is able to express the importance of a specific generator which plays its part in the system. The index is evaluated by varying load demands in every load buses.

$$
P_{G i, i n d}=\sum_{k=1}^{n} \frac{\Delta P_{\text {Gik }}}{\sum_{j=1}^{m} \Delta P_{G j k}}
$$

Each generator or plant has its own impact index. From (3), by a normalized arithmetic operation, $\tau_{\mathrm{i}}$ stands for the impact factor of generator $\mathrm{i}$ among the generators (from 1 to $\mathrm{n}$ ) in the system. Therefore, it is easy to validate that $\sum_{i=1}^{n} \tau_{i}$ equals to 1 and $\sum_{k=1}^{n} P_{G k, \text { ind }}$ shall be equal to the number of total generators or plants.

$$
\begin{aligned}
& \tau_{i}=\frac{P_{G i, i n d}}{\sum_{k=1}^{n} P_{G k, \text { ind }}} \\
& \sum_{i=1}^{n} \tau_{i}=1, \text { and } \sum_{k=1}^{n} P_{G k, \text { ind }}=n
\end{aligned}
$$

For all,

$\mathrm{P}_{\mathrm{Gi}, \text { ind }}$ : impact index of generator $\mathrm{i}$

$\mathrm{i}=1 \ldots . . . \mathrm{n}$ generators

$\mathrm{j}=1$.....m demand load buses

$\mathrm{k}=1 \ldots . . \mathrm{n}$ generators

Carbon dioxide emissions are regarded as main causes of global warming facts. There are many alternatives in price for carbon emissions [18]-[20]. One simple way is to charge polluters by piecewise payment [21]. In other words, more emissions will result in more penalties; however that has a maximum limitation to avoid overpaid and bad influence on economic activities. Fig.1 explains two policies in practicing the payment strategy. Table I shows $\lambda$, which is the price rate in various carbon emissions in terms of different regulating policies.

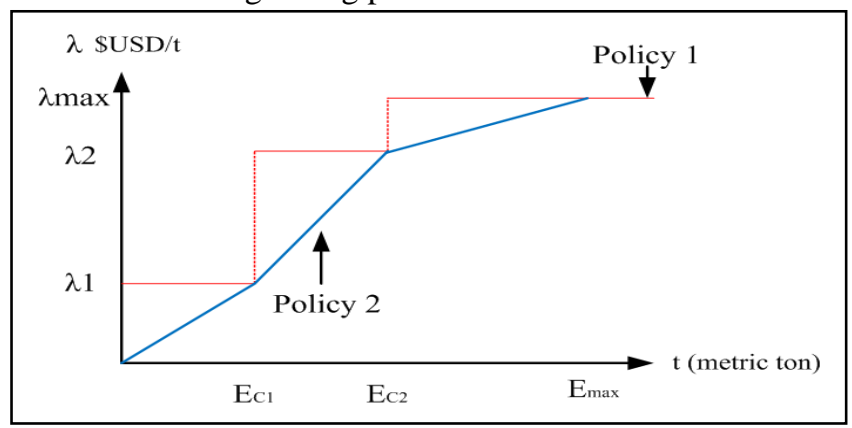

Fig.1. piecewise cost function of carbon emissions 
Table 1. Price rate of carbon emissions in various real power generations

\begin{tabular}{|l|l|l|}
\hline $\begin{array}{l}\text { carbon } \\
\text { generations }\end{array}$ & \multicolumn{1}{|c|}{ Policy 1 } & \multicolumn{1}{|c|}{ Policy 2 } \\
\hline$E_{C}<E_{C 1}$ & $\lambda=\lambda_{1}$ & $\lambda=\frac{\lambda_{1}}{E_{c 1}} \times E_{c}$ \\
\hline$E_{C 1}<E_{C} \leq E_{C 2}$ & $\lambda=\lambda_{2}$ & $\lambda=\left(\frac{\lambda_{2}-\lambda_{1}}{E_{c 2}-E_{c 1}}\right) \times E_{c}+\frac{E_{c 2} \lambda_{1}-E_{c 1} \lambda_{2}}{E_{c 2}-E_{c 1}}$ \\
\hline$E_{C 2}<E_{C} \leq E_{\max }$ & $\lambda=\lambda_{\max }$ & $\lambda=\left(\frac{\lambda_{\max }-\lambda_{2}}{E_{\max }-E_{c 2}}\right) \times E_{c}+\frac{E_{\max } \lambda_{2}-E_{c 2} \lambda_{\max }}{E_{\max }-E_{c 2}}$ \\
\hline$E_{C}>E_{\max }$ & $\lambda=\lambda_{\max }$ & $\lambda=\lambda_{\max }$ \\
\hline
\end{tabular}

The rule of marginal cost pricing is certificated to evaluate electricity price in the market of natural monopolies. Whereas the price is equal to marginal cost, it possibly brings about an effective allocation of resources. With respect to electricity, the proposed marginal cost pricing MCP is referred to (5).

Carbon dioxide emissions have gradually caused concerns relevant to global warming. Electricity consumed and production is a crucial issue whereas considering eliminating carbon emissions. To define the cost of carbon emissions and include it in electricity price is a way to reduce power consumption. For all power generation plants in the same network, variations in any load bus lead to changes of generator output. From the view of optimal power solution, the least cost of generator and minimum loss in power line is the target for commitment. Equation (6), introducing impact factors to relocate cost of carbon emissions, is an opportunity to make electricity price reasonably get revised and compensated. $\mathrm{E}_{\mathrm{i}}$ is reckoned as total carbon emissions of distinctive generation techniques. For instance, coal-fired and oilfired turbines emit different amounts of carbon emissions. The useful unit for this parameter is metric ton. Equation (7) specifies marginal carbon emissions cost (MCEC), which is equal to total carbon emissions divided by total load demand.

$$
\begin{aligned}
& M C P=\sum_{i=1}^{n}\left(\frac{d F_{C i}}{d P_{i}}\right)_{P_{i}=P_{G i}} \times \tau_{i} \\
& P_{T C C}=\sum_{i=1}^{n} P_{T C C, i}\left[E_{i}\left(P_{G, \text { Total }} \times \tau_{i}\right)\right] \\
& M C E C=\frac{\sum_{i=1}^{n} P_{T C C, i}\left[E_{i}\left(P_{G, \text { Total }} \times \tau_{i}\right)\right.}{\sum_{j=1}^{m} P_{L j}}
\end{aligned}
$$

There are two types of energy pricing mechanism in this model, uniform and locational energy price (Ep). Uniform Ep (Ep,uniform) is appropriate for only one power distribution company and provides the same electricity price for all customers in the same electric network. Refer to (8), a fixed or complicated profit rate could multiply total marginal cost to obtain final electricity price.

$$
E p_{\text {suiform }}=\left[\sum_{i=1}^{n}\left(\frac{d F_{C_{i}}}{d P_{i}}\right)_{P_{i=P_{c i}}} \times \tau_{i}+\frac{\sum_{i=1}^{n} P_{T C C, i}\left[E_{i}\left(P_{G, T_{\text {oual }}} \times \tau_{i}\right)\right.}{\sum_{j=1}^{m} P_{L j}}\right] \times \operatorname{Pr}
$$

The other pricing mechanism is locational energy price (Ep,locational). Electricity price changes in accordance with different load demand and network condition. Marginal cost pricing in power nodes is calculated in advance. Equation (9)-(13) follows the identical procedures of uniform energy price calculation in (5)-(8) to evaluate locational energy price in different load buses. 


$$
\begin{aligned}
& M C P_{j}=\sum_{i=1}^{n} \tau_{i} \times\left(\frac{d F_{C i}}{d P_{i}}\right)_{P_{i}=P_{G i j, N E T}} \\
& P_{G i j, N E T}=\left(P_{G i}-P_{T l o s s} \times \tau_{i}\right)+\frac{P_{L j}}{\sum_{j=1}^{m} P_{L j}} \times P_{T l o s s} \\
& M C E C_{j}=\frac{\sum_{i=1}^{n} P_{T C C, i}\left[E_{i}\left(P_{G i}\right) \times \tau_{i}\right] \times P_{L j}}{\sum_{j=1}^{m} P_{L j}} \\
& L M P_{j}=M C P_{j}+M C E C_{j} \\
& =\sum_{i=1}^{n} \tau_{i} \times\left(\frac{d F_{C i}}{d P_{i}}\right)_{P_{i}=P_{G i}}+\frac{\sum_{i=1}^{n} P_{T C C, i}\left[E_{i}\left(P_{G i}\right) \times \tau_{i}\right] \times P_{L j}}{\sum_{j=1}^{m} P_{L j}} \\
& E p_{\text {locational }, j}=\sum_{i=1}^{n} \tau_{i} \times\left(\frac{d F_{G i}}{d P_{i}}\right)_{P_{i=P_{G}}}+\frac{\sum_{i=1}^{n} P_{T C C, i}\left[E_{i}\left(P_{G i}\right) \times \tau_{i}\right] \times P_{L i}}{\sum_{j=1}^{m} P_{L i}} \times \operatorname{Pr}
\end{aligned}
$$

For all

$\mathrm{MCP}_{\mathrm{i}}$ : marginal cost price of generator $\mathrm{i}$

$\mathrm{F}_{\mathrm{Ci}}$ : cost function of generator $\mathrm{i}$

$\mathrm{P}_{\mathrm{Gi}}$ : power output of generator $\mathrm{i}$

$\mathrm{P}_{\mathrm{Gij}, \mathrm{NET}}$ : relocated power output of generator i for load bus $\mathrm{j}$

$\mathrm{P}_{\mathrm{Lj}}$ : demand load of bus $\mathrm{j}$

$\mathrm{P}_{\text {Tloss }}$ : total loss in an optimal power flow solution

$\mathrm{P}_{\mathrm{TCC}, \mathrm{i}}()$ :price of carbon emissions of generator $\mathrm{i}$

$\mathrm{LMP}_{\mathrm{j}}$ : locational marginal price of node $\mathrm{j}$

Pr: profit rate of generation plant

$\mathrm{P}_{\mathrm{G}, \text { Total }}$ : total generation amount

$\mathrm{E}_{\mathrm{i}}(\mathrm{)})$ carbon emissions of generator $\mathrm{i}$

\section{Problem Formulation}

Simulated Annealing algorithm is a probabilistic method proposed by Kirkpatric, Gelatt and Vecchi [22] for finding the global minimum solution of a cost function which possesses several local minima. It emulates the metal treatment where a solid finally reaches its frozen structure with minimum energy configuration [23].

MATPOWER is a Matlab-based power system simulation package which is able to supply high-level sets of power flow and optimal power flow solutions [24]. Compound Simulated Annealing and MATPOWER algorithm (CSAM) is able to solve AC and DC types of optimal power flow problems with multiple variables, not matter what the formulation and combinatorial functions are.

The following standard form of optimization problems is applied.

$$
\operatorname{Min} f(x, u)
$$

Subjects to

$$
g(x)=0
$$




$$
\begin{aligned}
& h(x) \leq 0 \\
& x_{\text {min }} \leq x \leq x_{\text {max }}
\end{aligned}
$$

$\mathrm{f}(\mathrm{x}, \mathrm{u})$ in (14) equals to a summation of fuel cost and cost of load valve effects, capacitor bank and carbon emissions. Equality constraints, $\mathrm{g}(\mathrm{x})$ in $(15)$, are nonlinear power balance equations, and $\mathrm{h}(\mathrm{x})$ is consisted of branch flow limits and bus voltage angles and magnitudes. The variables $\mathrm{x}$ which include bus angles, upper and lower limits of all buses and limits of real and reactive power injections to form inequality constraints. An equation in (18) is formulated to represent the overall cost function.

$$
\sum_{i=1}^{n} f_{P}^{i}\left(P_{G}^{i}\right)+\sum_{i=1}^{n} f_{P, \text { Lood }}^{i}+\sum_{j=1}^{n} Q_{j, \text { cost }}+\sum_{i=1}^{n} E_{i}\left(P_{G i}\right) \times \lambda_{i}
$$

Detailed descriptions are as follows:

3.1 Fuel cost- The fuel consumption which plays a major part of cost function in thermal power plants can be modeled by a quadratic form as follows:

$$
f_{P}^{i}\left(P_{G i}\right)=a_{i} P_{G i}^{2}+b_{i} P_{G i}+c_{i}
$$

3.2 Load valve effects- Control valves are possible to induce ripple effects in the input/output curve [25]. This term is able to describe as

$$
f_{P, \text { Load }}^{i}=\left|e_{i} \sin \left[f_{i} \times\left(P_{G i}^{M i n}-P_{G i}\right)\right]\right|
$$

3.3 Capacitor bank cost- The cost of capacitors could be calculated based on its capital investment. Lifespan of facility is defined as $\mathrm{n}$, and $\mathrm{r}$ is interest rate in the market. Ignoring maintenance cost, Net Present Value is applied to this evaluation.

$$
Q_{j, \text { cost }}=\frac{Q_{j, \text { investment }} \times(1+r \%)^{n}}{n \times 8760}
$$

3.4 Carbon emissions- It becomes a critical part in the modern environment issues. NOx emission might be a quadratic form of power generations. A certain portion of total emissions could be regarded as the amount of carbon emissions for simplification.

$$
E_{i}\left(P_{G i}\right)=\left(\alpha_{i} P_{G i}^{2}+\beta_{i} P_{G i}+\gamma_{i}\right) \times C_{p}
$$

3.5 Tap changer settings of transformers modulate bus voltage magnitudes.

Integrating above items, a vector $\mathrm{u}$ as shown in (23) represents control variables existed in the objective function [26]. All the units of subordinate cost functions are simultaneously adjusted to USD $\$ / h$.

$$
u=\left\{P_{G i} \ldots \ldots P_{G n}, Q_{j} \ldots \ldots Q_{m}, t_{i j}\right\}
$$

The procedure for implementing the model algorithm is illustrated in Fig.2. The operational flow is started from deciding load demand. The MATPOWER is an AC OPF solver to get basic index data of individual impact factors. Afterwards, By the CSAM algorithm, uniform and locational electricity prices are calculated respectively in the status of acquired near optimal solution to end the procedure. 


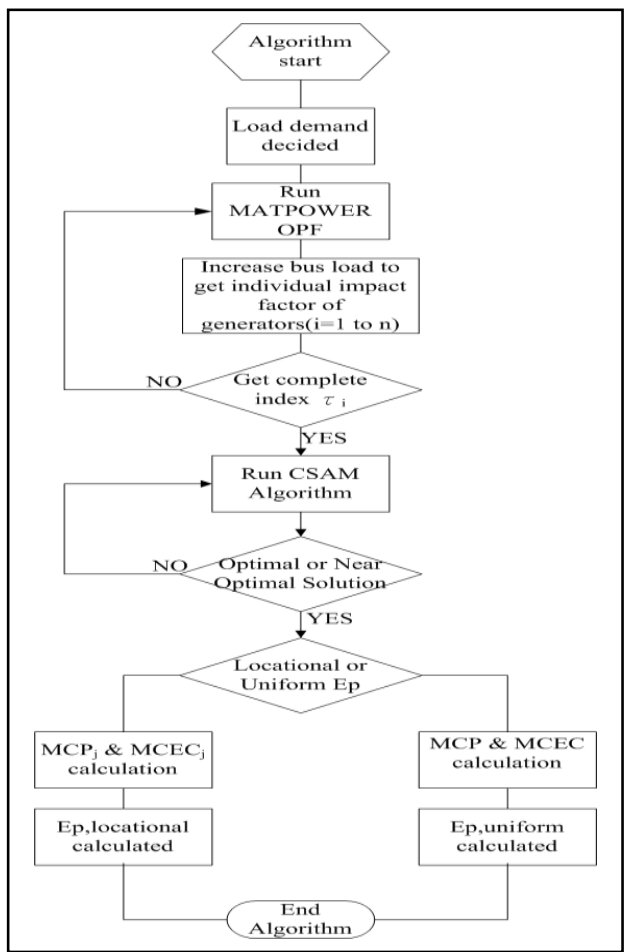

Fig. 2. the implementation procedure of the model algorithm

\section{Case Study}

There are three different cases of the IEEE-30 bus system for test example. Referring to Table $1, \lambda_{1}, \lambda_{2}$ and $\lambda_{\max }$ representing prices of carbon emissions are set to 3,4 and $5(\$ \mathrm{USD} / \mathrm{t}) . \mathrm{E}_{\mathrm{C} 1}, \mathrm{E}_{\mathrm{C} 2}$ and $\mathrm{E}_{\max }$ are equivalent to 10,30 and 70 (MW).

This test system includes 6 generators distributed at bus 1, 2, 13, 22, 23 and 27. For case 1, the cost function includes fuel, load valve effects and carbon emissions only. The MATPOWER AC OPF is appropriate for the calculation. In case 2, it is possible to compare results of case 1 and the proposed CSAM method. In case 3, all the variables involving transformer's tap changers and capacitor arrangements are put into practice to show the performance of the CSAM algorithm. The load demands are set at 20 buses.

Table II demonstrates the solution of case1. Whereas taking into account of uniform energy price, MCP is 3.822 and MCCE is 0.985 for policy 1 , and is 0.528 for policy 2. Considering a simplified profit rate, a fixed rate of $10 \%$, the electricity price (EP) is 5.288 and 4.785 \$USD/MWh respectively.

Table III shows the outcome of the proposed CSAM algorithm. In view of the same load condition, total cost is 778.533 and 737.34 respectively, which is definitely lower than the result of case 1. MCP is 3.909 and 3.920. MCCE is 0.980 for policy 1 , and is 0.524 for policy 2 . With regard to the same profit rate, the electricity price (EP) is 5.378 and 4.888 \$USD/MWh respectively. It is worth to note that policy 2 of carbon cost causes users to pay less electricity price because of adopting ramp rate in place of fixed number. Fig. 3 also illustrates the solution finding process. In the initial states, it is possible to jump to higher cost and then gradually reduce to stable status. That is a specific benefit of stochastic programming algorithms applied in the optimal solution solver.

Table IV and V illustrate the solution of the other iteration. In view of locational energy price mechanism, $\mathrm{MCP}_{\mathrm{j}}$ and $\mathrm{MCCE}_{\mathrm{j}}$ are determined. Transformer tap changers and capacitor displacement are contemplated as well whereas the capacitor bank is based on $300 \mathrm{kVar}$, and the tap changers are limited in 0.95 to 1.05 . Different generation commitments combined with capacitor settlements and tap changer 
adjustments can lead to another optimal solution and find their locational energy prices in spite of complicated cost function portfolio.

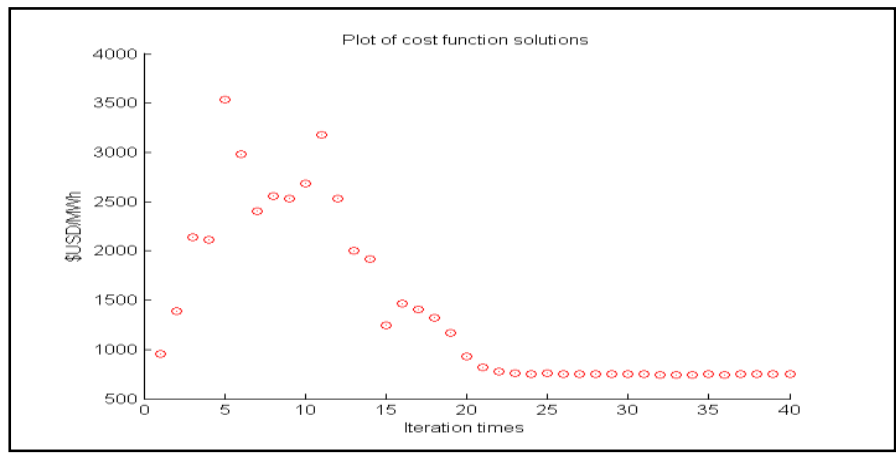

Fig.3. Solution of the CSAM algorithm

Table 2. Uniform pricing mechanism by the MATPOWER AC OPF

\begin{tabular}{|c|c|c|c|c|c|c|c|c|c|}
\hline & \multicolumn{2}{|c|}{ Symbol } & \multicolumn{6}{|c|}{ Generator (Supply) } & Demand \\
\hline & & & Gen1 & Gen2 & Gen22 & Gen27 & Gen23 & Gen13 & \multirow{6}{*}{192.2} \\
\hline Impact factor & \multicolumn{2}{|c|}{$\tau_{\mathrm{i}}$} & 0.167 & 0.194 & 0.6 & 0.226 & 0.185 & 0.169 & \\
\hline \multirow{2}{*}{ MCP(\$USD/MWh) } & \multirow{2}{*}{ MCP } & Policy1 & \multicolumn{6}{|c|}{3.822} & \\
\hline & & Policy2 & \multicolumn{6}{|c|}{3.822} & \\
\hline \multirow{2}{*}{ MCEC (\$USD/MWh) } & \multirow{2}{*}{ MCEC } & Policy1 & \multicolumn{6}{|c|}{0.985} & \\
\hline & & Policy2 & \multicolumn{6}{|c|}{0.528} & \\
\hline \multirow{2}{*}{$\mathrm{EP}_{\text {,uniform }}(\$ \mathrm{USD} / \mathrm{MWh})$} & \multirow{2}{*}{$\mathrm{EP}_{\text {,uniform }}$} & Policy1 & \multicolumn{6}{|c|}{5.288} & \\
\hline & & Policy2 & & & & 4.785 & & & \\
\hline Generation(MWh) & \multicolumn{2}{|c|}{$\mathrm{P}_{\mathrm{Gi}}$} & 40.83 & 54.54 & 23.11 & 40.47 & 19.08 & 17.18 & \\
\hline Total loss(MWh) & \multicolumn{2}{|c|}{$\mathrm{P}_{\text {Tloss }}$} & \multicolumn{6}{|c|}{3.001} & \\
\hline \multirow{2}{*}{ Total Cost (\$USD/MWh) } & \multirow{2}{*}{$\mathrm{f}(\mathrm{x}, \mathrm{u})$} & Policy1 & \multirow{2}{*}{\multicolumn{6}{|c|}{$\begin{array}{l}836.015 \\
784.521 \\
\end{array}$}} & \\
\hline & & Policy2 & & & & & & & \\
\hline
\end{tabular}

Table 3. Uniform pricing mechanism by the CSAM algorithm

\begin{tabular}{|c|c|c|c|c|c|c|c|c|c|}
\hline & \multicolumn{2}{|c|}{ Symbol } & \multicolumn{6}{|c|}{ Generator (Supply) } & Demand \\
\hline & & & Gen1 & Gen2 & Gen22 & Gen27 & Gen23 & Gen 13 & \multirow{14}{*}{192.2} \\
\hline Impact factor & \multicolumn{2}{|c|}{$\tau_{\mathrm{i}}$} & 0.167 & 0.194 & 0.6 & 0.226 & 0.185 & 0.169 & \\
\hline \multirow{2}{*}{ MCP(\$USD/MWh) } & \multirow{2}{*}{$\mathrm{MCP}$} & Policy1 & \multicolumn{6}{|c|}{3.909} & \\
\hline & & Policy2 & & & & .920 & & \\
\hline \multirow{2}{*}{ MCEC (\$USD/MWh) } & \multirow{2}{*}{ MCEC } & Policy1 & \multirow{2}{*}{\multicolumn{6}{|c|}{$\begin{array}{l}0.980 \\
0.524\end{array}$}} & \\
\hline & & Policy2 & & & & & & & \\
\hline \multirow{2}{*}{$\mathrm{EP}_{\text {,uniform }}(\$ \mathrm{USD} / \mathrm{MWh})$} & \multirow{2}{*}{$\mathrm{EP}$, uniform } & Policy1 & \multirow{2}{*}{\multicolumn{6}{|c|}{$\begin{array}{l}5.378 \\
4888\end{array}$}} & \\
\hline & & Policy2 & \multicolumn{5}{|c|}{4.888} & & \\
\hline \multirow{2}{*}{ Generation(MWh) } & \multirow{2}{*}{$\mathrm{P}_{\mathrm{Gi}}$} & Policy1 & 31.37 & 44.84 & 29.69 & 28.48 & 26.84 & 33.43 & \\
\hline & & Policy2 & 30.95 & 60.24 & 29.11 & 20.97 & 26.43 & 27.11 & \\
\hline \multirow{2}{*}{ Total loss(MWh) } & \multirow{2}{*}{$\mathrm{P}_{\text {Tloss }}$} & Policy1 & \multicolumn{6}{|c|}{2.443} & \\
\hline & & Policy2 & \multirow{2}{*}{\multicolumn{6}{|c|}{$\frac{2.610}{778.533}$}} & \\
\hline \multirow[t]{2}{*}{ Total Cost (\$USD/MWh) } & \multirow{2}{*}{$f(x, u)$} & Policy1 & & & & & & & \\
\hline & & Policy2 & \multicolumn{6}{|c|}{737.34} & \\
\hline
\end{tabular}


Table 4. Locational pricing mechanism by the CSAM algorithm

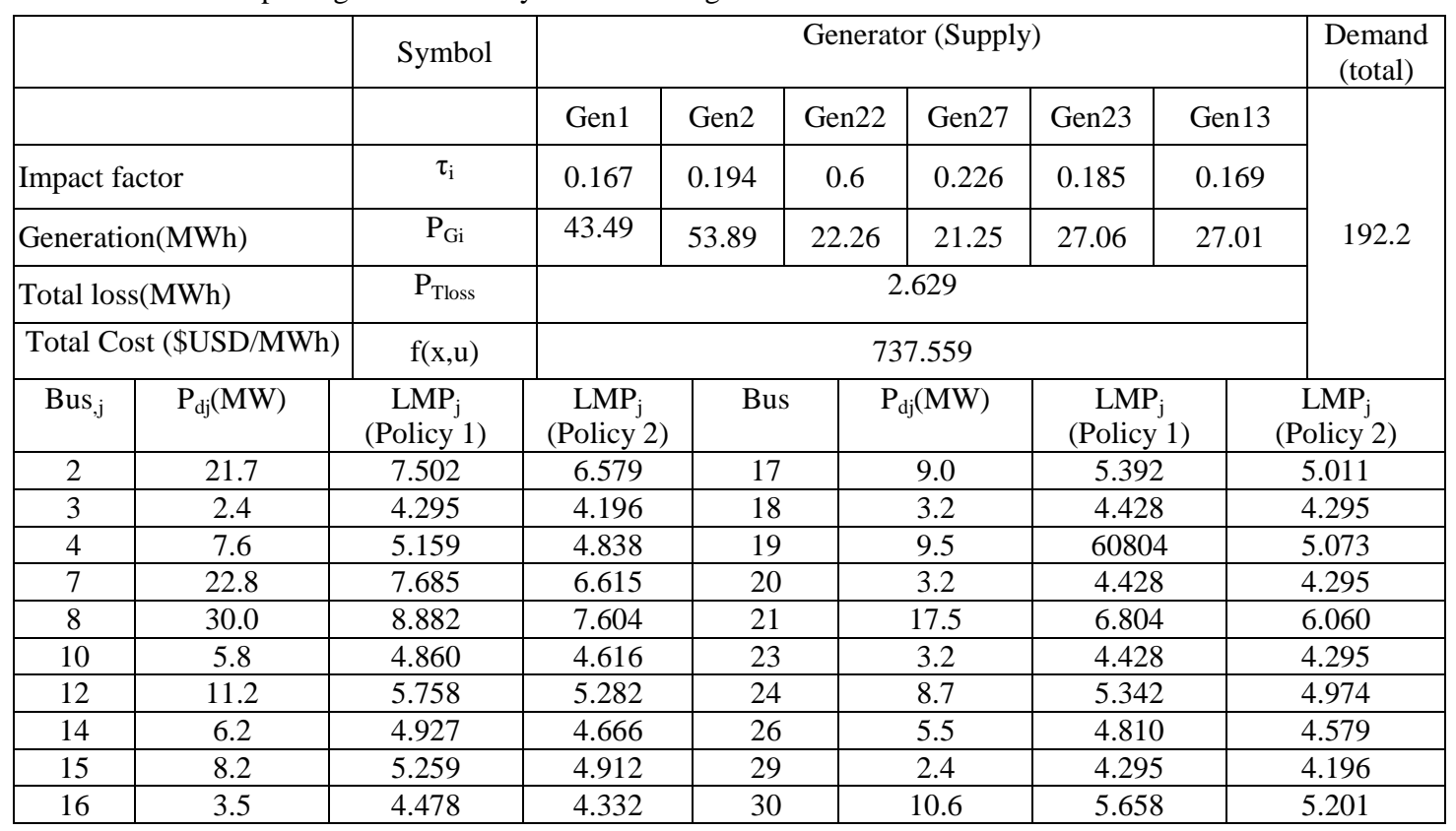

Table 5. Optimal setting of $\mathrm{Q}_{\mathrm{j}}$ and $\mathrm{t}_{\mathrm{ij}}$ in the IEEE-30 bus system

\begin{tabular}{|c|c|c|c|}
\hline Bus & $\mathrm{Q}_{\mathrm{j}}(\mathrm{MVar})$ & Branch & Tap changers setting \\
\hline 3 & 0.72 & 4-12 & 0.95 \\
\hline 4 & 1.5 & $6-9$ & 1.02 \\
\hline 5 & 0.33 & $6-10$ & 0.96 \\
\hline 6 & 0.24 & $27-28$ & 1.01 \\
\hline 7 & 0.36 & & \\
\hline 8 & 0 & & \\
\hline 9 & 1.5 & & \\
\hline 10 & 0.09 & & \\
\hline 11 & 1.08 & & \\
\hline 12 & 1.2 & & \\
\hline 14 & 1.38 & & \\
\hline 15 & 0.48 & & \\
\hline 16 & 0 & & \\
\hline 17 & 0.27 & & \\
\hline 18 & 0.96 & & \\
\hline 19 & 1.29 & & \\
\hline 20 & 0.54 & & \\
\hline 21 & 1.02 & & \\
\hline 24 & 1.08 & & \\
\hline 25 & 1.47 & & \\
\hline 26 & 0.15 & & \\
\hline 28 & 0.3 & & \\
\hline 29 & 1.29 & & \\
\hline 30 & 0.66 & & \\
\hline
\end{tabular}




\section{Conclusion}

It may be stated from above work that acceptable results have been acquired by the proposed model and flow chart. The basic content of electricity price consists of marginal cost pricing and cost of marginal carbon emissions. The uniform and location electricity price are calculated in the test system respectively. The impact factors are contributed to fairly relocate cost of generation and carbon emissions as well. The test results show that the CSAM algorithm carries out a fast speed and accurate solution solver of electricity price based lower total cost. Furthermore, real time energy price with cost of carbon emissions makes the sustainable environment viable. It is not only to have an attitude of looking for energy-saving, but also to obtain a basis framework of green energy pricing mechanism. The bus with more load demands, users will have to pay more prices to respond their request. It is possible for end users to think energy saving issues or locating distribution resources in the local communities.

There will be some critical surveys in the future. For example, a complicated generation cost function, embedded renewable energy source at distribution network, zonal energy price with pollution emissions. A predict of renewable energy and energy price integrated probabilistic demand forecasting is drawing our attentions toward it as well. Alternative stochastic programming algorithms applied in the optimal solution solver are also crucial issues for us to put effort on them.

\section{References}

[1] Wang L, Singh C. Environmental/economic power dispatch using a fuzzified multi-objective particle swarm optimization algorithm. Electric Power Systems Research, Oct. 2007; 77(12): 1654-1664.

[2] Gong D, Zhang Y, Qi CL. Environmental/economic power dispatch using a hybrid multi-objective optimization algorithm. International Journal of Electrical Power and Energy Systems, Jul. 2010; 32(6): 607-614.

[3] Wu LH, Wang YN, Yuan XF, Zhou SW. Environmental/economic power dispatch problem using multi-objective differential evolution algorithm. Electric Power Systems Research, Sep. 2010; 80(9): 1171-1181.

[4] Kai X, Song YH, Stonham J, Yu E, Liu G. Decomposition model and interior point methods for optimal spot pricing of electricity in deregulation environments. IEEE Transactions on Power Systems, Feb. 2000; 15(1): 39-50.

[5] Li F, Pan J, Chao H. Marginal loss calculation in competitive electrical energy markets. In: Proc. of Proceedings of the 2004 IEEE International Conference on Electric Utility Deregulation, Restructuring and Power Technologies, 2004. (DRPT 2004), 5-8 Apr. 2004; 1: 205-209.

[6] Litvinov E, Zheng T, Rosenwald G, Shamsollahi P. Marginal loss modeling in LMP calculation. IEEE Transactions on Power Systems, May 2004; 19(2): 880-888.

[7] Overbye TJ, Cheng X, Sun Y. A comparison of the AC and DC power flow models for LMP calculations. In: Proc. of the 37th Annual Hawaii International Conference on System Sciences, 2004; 1-9, 5-8 Jan. 2004.

[8] Cheng X, Overbye TJ. An energy reference bus independent LMP decomposition algorithm. IEEE Transactions on Power Systems, Aug. 2006; 21(3): 1041-1049.

[9] Orfanogianni T, Gross G. A general formulation for LMP Evaluation. IEEE Transactions on Power Systems, Aug. 2007; 22(3): $1163-1173$.

[10] Cardell JB. Marginal loss pricing for hours with transmission congestion. IEEE Transactions on Power Systems, Nov. 2007; 22(4): 1466-1474.

[11] Li F, Bo R. DCOPF-based LMP simulation: algorithm, comparison with ACOPF, and sensitivity. IEEE Transactions on Power Systems, Nov. 2007; 22(4): 1475-1485.

[12] Conejo AJ, Castillo E, Minguez R, Milano F. Locational marginal price sensitivities. IEEE Transactions on Power Systems, Nov. 2005; 20(4): 2026-2033.

[13] Peng JC, Jiang H, Xu G, Luo A, Huang C. Independent marginal losses with application to locational marginal price calculation. IET Generation, Transmission \& Distribution, Apr. 2009; 3(7): 679-689.

[14] Li F. Continuous locational marginal pricing (CLMP). IEEE Transactions on Power Systems, Nov. 2007; $22(4): 1638-1646$.

[15] Li F, Bo R. Congestion and price prediction under load variation. IEEE Transactions on Power Systems, May 2009; 24(2): 911-922.

[16] Bo R, Li F. Probabilistic LMP forecasting considering load uncertainty. IEEE Transactions on Power Systems, Aug. 2009; 24(3): 1279-1289.

[17] Chen L, Suzuki H, Wachi T, Shimura Y. Components of nodal prices for electric power systems. IEEE Transactions on Power Systems, Feb. 2002; 17(1): 41-49.

[18] Aboumahboub T, Schaber K, Wagner U, Hamacher T. On the CO2 emissions of the global electricity supply sector and the influence of renewable power-modeling and optimization. Energy Policy, Mar. 2012; 42: 297-314. 
[19] Fu S, Ren Y. A motivating mitigation mechanism for generators on condition of coordinated regulation of emission and electricity market. International Journal of Electrical Power and Energy Systems, June 2011; 33(5): 1151-1160.

[20] Levin T, Thomas VM, Lee AJ. State-scale evaluation of renewable electricity policy: The role of renewable electricity credits and carbon taxes. Energy Policy, Feb. 2011; 39(2): 950-960.

[21] Roy P, Sen S, Sengupta S, Chakrabarti A. Genetic algorithm based spot pricing of electricity in deregulated environment for consumer welfare. 2010 International Conference on Electrical and Computer Engineering (ICECE 2010), Dec. 2010; 271$274,18-20$.

[22] Kirkpatrick S, Gelatt CD, Vecchi MP. Optimization by simulated annealing. Science, May, 1983; 220(4598): 671-680.

[23] Bertsimas D, Tsitsiklist J. Simulated annealing. Statistical Science, 1993; 8(10): 10-15.

[24] Zimmerman RD, Murillo-Sánchez CE, Thomas RJ. MATPOWER: Steady-state operations, planning, and analysis tools for power systems research and education. IEEE Transactions on Power Systems, Feb. 2011; 26(1): 12-19.

[25] Walters DC, Sheble GB. Genetic algorithm solution of economic dispatch with valve point loading. IEEE Transactions on Power Systems, Aug. 1993; 8(3):1325-1332.

[26] AlRashidi MR, El-Hawary ME. Hybrid particle swarm optimization approach for solving the discrete OPF problem considering the valve loading effects. IEEE Transactions on Power Systems, Nov. 2007; 22(4): 2030-2038,.

[27] Lukic SM, Mulhall P, Emadi A. Energy autonomous solar/battery auto rickshaw. Journal of Asian Electric Vehicles, 2008; 6(2):1135-1143. 